\title{
Hereditary Pancreatic Carcinoma
}

National Cancer Institute

\section{Source}

National Cancer Institute. Hereditary Pancreatic Carcinoma. NCI Thesaurus. Code C43298.

A carcinoma that arises from the pancreas in a patient with a family history of pancreatic cancer. In the minority of cases, patients have recognized genetic syndromes (e.g.,

FAMMM syndrome, BRCA2 syndrome, Peutz-Jeghers syndrome) however, in the majority of cases the genetic cause has not been identified. 